\title{
Is Information a Sufficient Basis for Cognition? Part 1: Critique of Dretske's Approach
}

\author{
José María Díaz Nafría*, Mario Pérez-Montoro** \\ “jdian@unileon.es, Science of Information Institute, Washington, U.S.A; Universidad de León, Spain \\ "perez-montoro@ub.edu, Department of Information Science, University of Barcelona, Spain
}

\begin{abstract}
Based upon the natural limits of observation, we tackle a critical review of Dretske's approach to information, knowledge and perception. The physics of the manifestation of an arbitrary object-tackled in Part 2 as a separate articlesets forth an informational boundary stating that information cannot be enough to support our cognitive processes. The problems do not rely -as Dretske supposes- on the lacks of the channel, but on the very nature of observation. Furthermore, Dretske's approach -handcuffed to his maximalist support on information- presents some lacks concerning processual character of information, fuzziness of perception and knowledge, contents de dicto and conventional regularities. The posed limits and problems intend to settle new foundations for a more refined conjunction of information and knowledge.
\end{abstract}

Keywords: Physics of observation, Waves, Inverse problem, Theory of perception, Biophysics, Dretske, Epistemology, Communication, Cognition, Signal, Information content, Information flow

Acknowledgement: The authors wish to express special thanks to the organizers of FIS2010 (Beijin) for their kind invitation and to Mary Jo Deering whose generosity has made possible our participation. We are also deeply grateful to Prof. Mercedes Osorio and Dr. Rosa Macarro for their openhanded and careful effort in revising the article, as well as to Prof. Juan Lara (at the University of Salamanca) for his valuable comments, suggestions and critics in the biophysics of perception. About 10 years ago, Prof. Fernando Las Heras (at the University of Oviedo) sowed the seeds for our physical analysis of observation firstly devoted to electromagnetic fields; we also thank his valuable thrust.

\section{«Nihil est in intellectu quod prius non fuerit in sensu, nisi ipse intellectus»}

In the traditional thesis of the tabula rasa, which is coherent with the first part of this Latin motto, intellection plays a rather passive role, something as a reservoir for a diachronic perception of reality. Giving intellection a more active task in the procedural interpretation of sense, it is conceived as a computational power which enables to find out -from the rough information provided by sensation- what is not directly sensed. Leibniz liked to stress the second part of the previous motto to remark the importance and relative independence of such intellective power. However, in the opposite side, the idealistic tradition understands intellection as an autonomous faculty which drives the apprehension of reality by means of a proper (in the sense of intellectually suitable) arrangement of sensual data.

In spite of a higher or lower role of intellection and sense, there is something in common to these three conceptions of knowledge: sensation and intellection are considered as different faculties, to which different acts correspond: the act of sensing reality, and the act of intellecting reality.

When the philosopher Fred Dretske published in 1981 Knowledge and the Flow of Information $(\mathrm{KFI})$, he re-founded the tabula rasa with the new brand of digital perception and knowledge, finding (digital) information as a sure support for correct cognition, and providing the essential structure for much of the philosophy that followed. Dretske aimed at making a conceptual journey through the territory of mental states and developing a semantic theory of information, a useful tool that would allow thinkers to analyze the most important mental processes involved in cognitive behavior, such as knowing and believing.

Dretske's approach provides prima facie a solid base to tackle the knowledge problem and its representation. However, a deeper analysis drives us to different conclusions. We try to show based on the physical analysis of the manifestation of reality- that his very core idea of (digital) 
perception and information actually faces severe limitations invalidating his proposal as a whole and inviting us to leave it aside.

First we will review the fundaments of Dreske's approach; in part 2 (separate article ${ }^{1}$ ), we will analyze the very nature of observation and perception, which imposes some basic epistemological constraints not attained to the reliability of channels or sensors, but to the nature of the manifestation of an object in its environment. Finally, based upon this epistemological boundary and other characteristics of perception, knowledge and information, we will show the errors presented by Dretske's approach, bringing forward a new proposal. Alike the three aforementioned traditions (which consider sense and intellection as different faculties), this proposal questions the Latin motto in a radical different way: is reality not being actually apprehended in a unitary act of sensing and understanding within the limits of both reality itself and the complex structure of a sentient intelligence ${ }^{2}$ ?

\section{Dretske's Approach}

\subsection{Information}

Dretske's analysis aims to present a semantic theory of information, a theory of the propositional content of a signal. One of the best ways to do this is to begin with a declaration of principles. Throughout KFI, the commodity called "information" must be considered as something objective and natural, whose existence, generation or transmission does not depend on the cognitive interpretation of a possible agent. Any event that is a part of the world can be considered to be a signal that conveys information. This is why, in evolutionary terms, information preceded its users.

Once this explanation of philosophical principles has been proposed, Dretske, searching for a possible definition of informational content that can serve as part of the scaffolding for further analysis, presents a series of constraints that are crucial to any theory aiming to provide a definition of informational content. The first essential condition is a constraint of a communicational nature derived from the mathematical theory of communication (Shannon \& Weaver, 1949). This constraint is deduced from the values of the amounts of information involved in the flow or exchange of information. Specifically, in order for a signal $r$ to carry the information that $s$ is $F$, the following condition must be fulfilled:

(a) The signal carries as much information about $s$ as would be generated by s's being $F$. (Dretske, 1981, p. 63)

However, in addition to this communicational constraint, a signal must fulfill other conditions to carry the information that $s$ is $F$ :

(b) $s$ is F. (Dretske, 1981, p. 64)

(c) The quantity of information the signal carries about $s$ is (or includes) the quantity generated by s's being $F$ (and not, say, by s's being $G$ ). (Dretske, 1981, p. 64)

Condition (b) requires, if $r$ carries the information that $s$ is $F$, which the event $s$ is $F$ really does occur. In contrast, constraint (c) indicates that although communicational condition (a) is fulfilled, and although $s$ really is $F$, for $r$ to carry the information that $s$ is $F, r$ must at least contain the information, not merely the quantity of information, generated by the fact that $s$ is $F$, and not by the fact that $s$ is anything else.

Thus, if a signal carries the information that $s$ is blue, according to these three constraints: $r$ must carry at least as much information about $s$ as the amount generated by the fact that $s$ is blue, $s$

\footnotetext{
${ }^{1}$ When we mention "part 2" (here and henceforth), we are referring to our article published within this special issue "Is information a sufficient basis for cognition? (part 2)", in which the nature of the manifestation of an reality and the nature of perception are analyzed.

${ }^{2}$ Although we will not delve here into the very rich analysis of reality, sense, understanding and reason developed by the Spanish philosopher Xavier Zubiri, some of his concepts, for instance, sentient intelligence (developed in the homonymous book) will be used in our proposal, especially in §3 (Zubiri, 1999).
} 
must be blue, and the amount of information about $s$ carried by signal $r$ must be at least that generated by the fact that $s$ is blue, and not, for instance, by the fact that $s$ is red.

Once Dretske has presented these constraints, which all definitions of information need to take into account, he is able to specify the necessary and sufficient condition to be able to assign a specific informational content to a signal. This condition, on which his definition of informational content is based, in addition to the constraint that (a) specifies, is derived from the quantitative treatment specified in the mathematical theory of communication:

(1) Definition of informational content: $A$ signal $r$ carries the information that $s$ is $F=$ the conditional probability of s's being $F$, given $r$ (and k), is 1 (but given $k$ alone, less than 1). (Dretske, 1981, p. 65)

In definition (1), $k$ represents what the receiver of the signal knows about the different possibilities that exist at the source.

This definition is complemented by what Dretske calls the Xerox principle. This is a regulatory principle inherent in and essential to the idea of information, and one that any theory of information must take into account:

(2) Xerox principle: If $A$ carries the information that $B$, and $B$ carries the information that $C$, then A carries the information that C. (Dretske, 1981, p. 57)

In his analysis of informational content, we can see that Dretske distances himself from the fundamental concepts of the mathematical theory of communication, although he extracts from this theory a constraint and a necessary and sufficient condition for the existence of informational content, and he also maintains the idea of the measure of information in terms of inverse probabilities. The main difference between the two approaches is very clear. On the one hand, in Shannon's theory the focus is exclusively on the statistical properties derived from a set of events (sources of information). However, in KFI, for semantic and epistemological reasons, the focus is on the amount of information associated with signals or individual events since it is these and not the sources that are able to convey informational content.

To this regard, we question: is there not a further constraint in the determination of these signals with respect to the different possibilities of the source as to surely assert that $\mathrm{s}$ is $\mathrm{F}$ ? If this were the case, as we will try to show later, then the deterministic condition $(p=1)$ in the necessary and sufficient condition (1) is not very realistic and we should rather admit a weaker determination.

\subsection{Knowledge}

Once Dretske has presented his definition of informational content, he is able to offer us a definition of de re perceptual knowledge based on the theory of information:

(3) Definition of de re perceptual knowledge: $K$ knows that $s$ is $F=K$ 's belief that $s$ is $F$ is caused (or causally sustained) by the information that $s$ is F. (Dretske, 1981, p. 86)

In this definition, the phrase "belief that is caused by information" must be understood as the belief caused by the information contained in the fact of $s$ being $F$. Furthermore, by "information that causes a belief," the following is understood: "When ... a signal carries the information that $s$ is $F$ by virtue of having property $F$ ', when it is the signal's being $F$ ' that carries the information, then (and only then) will we say that $s$ is $F$ causes whatever the signal's being $F^{\prime}$ causes" (Dretske, 1981, p. 87).

This means that the internal content of a belief expressed by the utterance "s is F" is caused by the information that $s$ is $F$ if and only if the physical properties by virtue of which the signal carries the information that $s$ is $F$ are the same properties that are causally effective in producing the belief. Thus, it might seem at first that only the physical properties of the signal - and not the information that it contain - are necessary to produce the belief. Although this may not be immediately evident, to introduce the requirement of information over and above the requirement of the physical properties that produce the belief is not gratuitous or redundant: this will help us discern which of 
these properties are responsible for the construction of the belief and its subsequent transformation into knowledge.

What must be understood by "causally sustaining a belief" is that K's belief that $s$ is $F$ is causally sustained or maintained by the information that $s$ is $F$ if and only if this information affects the belief in such a way that the information would be sufficient for the existence of the belief in the absence of any contribution from other causes. Thus, we can prevent beliefs created in the absence of information from being identified as knowledge. An individual $\mathrm{K}$ might believe that $s$ is $F$ because a friend, who has no idea whether or not $s$ is $F$, has told him that $s$ is $F$. For example, let us suppose that without knowing it, K's friend has told him the truth since the fact $s$ is $F$ is just what happened in reality. Later, $\mathrm{K}$ can establish-receiving the information that $s$ is $F$ through his perceptual system-that $s$ really is $F$. In this case, $\mathrm{K}$ will find out that $s$ is $F$, not because his belief has been caused by what his friend told him, but rather because this belief has been causally sustained by the information that $s$ is $F$. If $\mathrm{K}$ had only received the indication from his friend, his belief that $s$ is $F$ would not be knowledge. On the other hand, if K's belief had been caused by the information that $s$ is $F$, this would have been enough for this belief to be identified as the knowledge that $s$ is $F$.

Thus, returning to the definition of knowledge and of informational content, for $\mathrm{K}$ to know something, $\mathrm{K}$ must have information about this with a probability equal to 1 ; therefore, to know that $s$ is $F$ requires not only a sufficient amount of information about $\mathrm{s}$, but also precisely the information that $s$ is $F$ based on the very physical properties of the signals carrying such information. However, are these physical properties sufficient to assure this fact? Or $k$ is rather sustained by some probable or undetermined relations? To answer this, we will delve into the physical relations of signals and the observed object, just after taking into consideration Dretske's understanding of perception and perceived object.

\subsection{Perception}

Dretske introduces a fundamental difference between causal and informational relationship, by means of which he distances himself from the Causal Theory of Perception. Based upon digital encoding of information, ${ }^{3}$ he ascribes perception to informational relations (regulated by constraints (a)-(c)). Within this frame, Dretske assigns an important role to information in the explanation of the sensory and cognitive processes that allows him to present a clear definition of objects of perception. The perceived object is that component in the causal sensorial chain about which the perception carries information, in contrast to the rest of the components in the same chain. In the end, the perceived object is the causal antecedent of the chain that is selected as the object of the perceptual state. This selection is realized by means of a primary representation of this object in the perceptual process:

$S$ gives primary presentation to $B$ (relative to property $G$ ) $=$ S's representation of something's being $G$ depends on the informational relationship between $B$ and $G$ but not vice versa (Dretske, 1981, p. 160).

\section{Limits of Dretske's Approach and the Fundaments of Cognition}

After having considered in $\S 1$ the main elements of Dreske's framework to understand information, knowledge and perception, we will examine within this section the limits of this approach based on the results obtained in the physical inquiry of the observational limits and the analysis of perception (both developed in the Part 2$)^{4}$.

\footnotetext{
3 "I will say that a signal [...] carries the information that $\mathrm{s}$ is $\mathrm{F}$ in digital form if and only if the signal carries no additional information about s, no information that is not already nested in s's being $F^{\prime}$ (Dretske, 1981, p. 137). In perceptual process, further (analog) content carried by signals are considered as noise and ignored as such.

${ }^{4}$ In our article "Is information a sufficient basis for cognition? (part 2)", we set forth the mathematical and physical foundations for the following analysis. Due to the fundamentality of the conclusions reached in our physical analysis, we strongly recommend to have read $\S 2.6$ and $\S 3$ of part 2 before reading $\S 2$ of the current article.
} 


\subsection{Information, "Objective Commodity" vs. "Process"}

In spite of Dretske's intent of presenting information as an objective commodity, when we take his interpretative framework of \{information, knowledge, perception and learning\} as a whole, Dretske's understanding of information can rather be interpreted as a process. This informational process consists in a digitalization of the world (see note 3), constituted by a learning process in which the subject learns to distinguish that $s$ is $F$, as from the surely means of the signals (PérezMontoro, 2007, pp. 83-85; pp. 124-126).

Of course, Dretske is aware that $s$ can be something else or something beyond being F. However, if that is not surely determined by the signals and the previous knowledge, the signals which could carry an indication that $s$ might be for instance $G$ are just junk, noise, something that the perceptual digitalization will take away. Signals do not convey information in Dretske's point of view unless they bring about to the "synchronic receiver" the certitude that something is the case. When we talk about the "synchronic receiver" we mean the one which receives all the signals coming from its world in his interaction with it, although this interaction, which actually constitutes the perceptual apparatus as it really works, is rather a slow, diachronic process. Therefore, this "synchronic receiver" holds the currently received signals together with the previous ones substantiated in his knowledge, acting as a perceptual mechanism (discriminating information from noise). By these means, we wish to stress Dretske's idea of knowledge as just caused by information in his long interaction with reality, at the same time that we emphasize the actual character of information as process in his own vision.

\subsection{Certitude, Fallibility and Channel Conditions}

Considering the mentioned process \{information, knowledge, perception and learning\} as a whole, Dretske could have stated that knowledge is caused by signals, since nothing else than signals are what the recipient receives from the world, but that would collapse his entire scaffold. The fact that the relation between the signal and the observed events has to be sure (which he stresses in def.1 with the condition of probability $=1$, perhaps in order to avoid any bad interpretation) is an essential element of his framework. Signals do not have such property; information is encapsulated in signals in virtue of a sure relation, which he even calls "informational relationship" (Dretske, 1981, p. 160). If a signal does not convey information it is junk, noise and ignored as such. Since the certitude of def. 1 is founded on the recipient's knowledge, i.e. previous perceptions and therefore signal receptions, we should ask -making a Cartesian analysis of this issue-: What is the first perceptual certitude (not conditioned to any previous experience) which enables the recipient to be sure that it is the case (i.e. having the form: given $r$, " $s$ is F" with probability =1)? As we know, Descartes' analysis on this concern is that the only indubitable event was the sure truth of his doubt. We are not claming for Cartesian correctness; on the contrary, we are just appealing to the problem which entered modernity into the circularity of idealism based on its claim for sureness, just the cornerstone of Dreske's scaffold.

Beyond any rhetoric we speak about 'cornerstone' just because if aiming at avoiding an unnecessary excess we change in Dretske's def. $1 p=1$ for $p \cong 1$ (being smaller though as close as we want), then with the passage of time the "diachronic observer" would not have a clear criteria (qualitative rather than quantitative) to distinguish between knowledge and belief, as Dretske intended.

Of course, Dretske is aware of the limitations of his definition of informational content in its attempt to give an account of the degree of fallibility or error exemplified by the regularities supporting information, and he dedicates an entire chapter of his work to this topic (Dretske, 1981, §5). However, to keep his definition intact and, as we have argued before, also the rest of his framework, he completes def. 1 with the condition that the "communication channel" must "work correctly". If the channel conditions are fulfilled, errors might not occur (Pérez-Montoro, 2007, pp. 116123). From Dretske's vision: a world of perfect channels would not be a realm of truth? Again, the 
digitalization process as the means to prevent noise into recipients is in the very core of his conception.

Nevertheless, here Dretske distances from Shannon's Mathematical Theory of Communication (MTC) since the latter speaks about an "arbitrarily small equivocation" (Shannon, 1948, theorem 11 ), which is not the same that $p=1$, but, as we mentioned before, $p \cong 1$ (as close as we want, but smaller). What condition should a channel accomplish to work correctly in Dretske's sense? Considering, on the one hand, that the noise should not be under certain levels but equal to absolute zero, otherwise the error probability in digital reception could be arbitrarily small but not zero; and on the other hand, that the unavoidable thermal noise is temperature-dependant: there is probably no other way to accomplish Dretske's condition -in virtue of the third law of thermodynamics- than jumping out of our universe to a space of absolute zero temperature, which besides would not be very interesting for living beings.

What we wish to stress is that there is not a quantitative change from moving from Dretske's certitude to a relatively high certitude, but a deep qualitative change: we might be speaking about something beyond the world or something going on in the world, as for instance perception, information or knowledge.

\subsection{Towards a More Coherent Fundament of Cognition}

If, in our previous analysis of the physical manifestation of the object (Dretske's signals), they do not suffice to support Dretske's certitude and this is not something gratuitous in Dretske's framework, then we have to find for a different foundation for cognition beyond the digital form of perceiving informational relations. One strategy could be: instead of searching an informational support for semantics -as Dretske-, doing it the other way round, namely, searching for a semantic support of information. ${ }^{5}$ Of course, as it happens with Dretske's approach, the whole conception depends on our conception of information (Díaz, 2010), and this is something that is far from being univocally solved (Díaz \& Salto, 2009). But apart from this intriguing discussion, we believe there is a fundament of cognition which at the same time depends on reality itself and on the complex structure of perception and intellection. Reality and this structure join in a unitary act by means of which the subject senses reality and -so to speak- its transcendence, in the sense that an object is never sensed as something closed and determined but open, with and in relation to other objects, in an environment, in a pragmatic situation, always holding an unveiled part, and being ambiguous to some extent (i.e. with the possibility of being something else). This is what Zubiri (1999) names "sentient intelligence", and we believe it provides a radical otherness in the basis for cognition.

\subsection{Digital vs. Fuzzy Fundaments of Semantics}

It could be argued that although Dretske's channel conditions are inflated as to be supported by reality, his constructs might play the role of good regulatory ideas akin Shannon's noiseless channel. However, in contrast to Shannon, who clears his course of dealing with semantic or pragmatic questions, Dretske - openly - intends to overcome this limitation bringing about a robust support for learning, knowing and perceiving by means of the digital form of information (s. note 3). Nevertheless if we delve into Shannon's communication model, it is the solved question of digital information that allowed Shannon to just deal with syntactic questions. Defining the elements of the digital mode (i.e.: symbols, relations among them, combinatory rules, reliability of the symbolic set with regard to the communication purposes, etc.) is properly entering into the syntactic and pragmatic realm (Díaz \& Hadithi, 2009). Thus, taking for granted the digital form of informational content is to our understanding an improper way for tackling with semantics as Dretske intends to. In other words, it is taking for solved what he should explain as basis for the rest of his scaffold. The consequence is again the erection of a coherent stage on which no reality is presented.

\footnotetext{
${ }^{5}$ Søren Brier criticizes these two approaches naming them informational- and semiotic views, and proposes an intermediate approach integrating cybernetics and Peircean semiotics in what he calls cybersemiotics (Brier, 2008).
} 
As we have argued in the physical analysis of observation (Part 2, §2) and the nature of perception (Part 2, §3), there is a constitutive insufficiency in the manifestation of reality as to surely assert that $s$ is $F$. In contrast, we can surely say that $s$ manifests itself, i.e., its existence can be surely noted. But asserting that it is $F$ is something whose certitude depends on the essential fuzziness of the manifestation of $s$ and the fuzziness of being $F$. In contrast with the Dretskean digital form of informational relations, which is based on the deterministic process of digital reception, we believe that there is an essential fuzzy aspect of knowledge, semantics and information (Díaz \& Hadithi, 2010). Whereas in the process of digital reception of a communicating item - which plays a heuristic role in Dretske's vision -, the process ascribes a deterministic value from the signals being received (e.g. if the signaled temperature is $37^{\circ} \mathrm{C}$ or above, the patience has fiber), in our real awareness of reality, the process is not univocally determined (e.g. under or above $37^{\circ} \mathrm{C}$ we might say with different degree of certainty that the patience has a fever; if (s)he is over $38^{\circ} \mathrm{C}$ we can be quite sure).

This fuzziness of our assessments is to our belief not something completely arbitrary but the proper way of taking awareness of a reality which manifests itself fuzzily. As we have shown above, there is not a digital manifestation of reality, but rather an incomplete, blurred one. On the other hand, the objects manifest themselves as open to a broader reality, to what we might name "world", considered as a formal and physical unity (Zubiri, 1999, §4.2.2). Intellective apprehending reality means to grasp this essential openness, which must be understood also dynamically. ${ }^{6}$

\subsection{A Fuzzy-Digital Formality of Perception}

In spite of this ungraspable reality, we dramatically have to deal with the world, i.e. -as any other living being- we have to fulfill our necessities; we have to survive. Considering again the simpler case of a unicellular organism, which feels its environment within a limited range of changes corresponding to its survival conditions, the way of sensing these changes is not digital. For instance, as the study of the movement of the Euglena in relation to light variations has proven, rather fuzzy and analogical rules regulate its movement (speed variation, flagellar beating frequency, orientation towards light) and because of the direct connection of the sensing structure to the motor one, this can only be due to a fuzzy feeling of the light conditions (e.g. it is dark, the light is good, the light is too bright) (Ascoli, 1978; Richter et al., 2002). Probably if the light sensing of the Euglena were not fuzzy its behavior would not be appropriated. Let the eyespot's light strength reception be digital and the Euglena be in the dark side of an environment whose illumination increases gradually. If it had to wait until the light got over a threshold, it would not be able to feel any change in the brightness, and therefore, it would lose the opportunity to slowly move towards the bright side, probably dying in the dark side. ${ }^{7}$

It could be argued, at the cellular level, that many mechanisms respond to a digital form. For instance, the ligand-gated ion channel opens or closes the channel whether or not a specific ligand (a signal triggering molecule) is being received (EBI, 2010). However, this and other digital receiving structures of the cell are usually part of specialized cells having specific functions in a higher organized pluricellular organism. In the example, the ligands act as messengers to regulate the cell function in this organism (e.g., it must activate for transmitting a nervous impulse). Therefore, here it is not the feeling of the environment what is in question but the communication process in the organization of a more complex system.

\footnotetext{
${ }^{6}$ In our previous physical analysis of observation, we did not consider the temporal change for the sake of simplicity. However, considering the symmetry of ec. (1) with respect to the spatial and temporal variables, if we include time changes, we would find analogous consequences: the object manifestation is three dimensional, whereas it properly has four dimensions, which is coherent with Beckenstein corollary of the holographic universe (s. note 6 of Part 2; Bekenstein, 2003).

${ }^{7}$ To mention a more general example: the cell can have the ability to feel the inner excess of acids and act accordingly. The Voltage-gated proton channels, which detect depolarization in $\mathrm{pH}$ dependence, directly regulate the conductivity of the channel to protons for acid extrusion. Instead of opening or closing the channel it can be regulated by a fuzzy rule: closed, semi-opened or opened in dependence with the voltage and pH (Cherny, Markin, \& DeCoursey, 1995).
} 
Let us now consider the even more complex case of the animal vision, for instance, perceiving that what we are seeing is an apple. If we formulate it very simplistically it might exhibit a digital form in Dretske's sense. However, when we are seeing what we have in front, we might actually perceive what has the formality of the apples as we have been dealing with till now. If somebody would ask us: is it really an apple? Then we would appeal to the openness that we also feel: we would like to see it closer, from a different angle, touch it, and so on. Whenever we go forward in our inquest, on the one hand, we complete the previous percepts, but on the other hand, we also feel the need for further notes (opening, tasting, planting its seeds, etc.). As we have previously analyzed, the object will never manifest completely, and we cannot indefinitely defer our asserts, for obvious pragmatic reasons (in other words, we may prefer having a fresh apple to being completely sure that it was an apple).

What we wish to stress is that Dretske's "nomic regularities" among types of events supporting the informational content and the digital perception of the world (i.e. establishing a sure univocal relation between facts and signals, what we intentionally have named manifestation of the object) do not exist (Dretske, 1985, p. 185). Instead of such de re perception (§1.2) there is rather a fuzzy, de dicto perception, by means of which living beings (and we among them) grasp its environment in a fuzzy-digital formality mediated by conventional regularities. This fuzzy-digital formality can be synthetically expressed as: $s$ is $F$ with a confidence degree. At best there is no better assert about the sensed reality given the notes grasped from it and the pragmatic situation in which we are immersed (included eventual inquests for finding out if something is the case). Whereas the challenge in the Dretskean world of nomic regularities and informational relations would be the cleaning of communication channels, here our challenge is to find the optimal way of describing reality giving the attained evidences and our pragmatic objectives (in a much broader sense of pragmatism than the circumscribed to a close-, short-term finality), and - mutatis mutandis the example of figure 3 in part 2 - we must be ready to accept that what we are feeling might be something else that what we previously thought, which is coherent with the sensed open character of reality.

It is not that there is no real and direct relation between reality and its manifestation; it is not that our asserts are disconnected from reality. Quite on the contrary, there is a real relation between reality and its manifestation, but - in mathematical terms - it is surjective; there is a close connection between our asserts and reality, since it is the complex structure of our intellective sensation what provides us a truthful apprehension of reality.

In other words, from the first posed bi-horned dilemma of sense or intellection, we rather prefer to grab both horns.

\section{References}

Ascoli, C., Barbi, M., Frediani, C., \& Mure, A. (1978). Measurements of Euglena motion parameters by laser light scattering. Biophysical Journal, 24, 585-599.

Bekenstein, J. D. (2003). Information in the holographic universe. Scientific American Magazine, 289(2), 58-65.

Brier, S. (2008). Cybersemiotics: Why information is not enough. Toronto, CA: University of Toronto Press.

Cherny, V. V., Markin, V. S., \& DeCoursey, T. E. (1995). The voltage-activated hydrogen ion conductance in rat alveolar epithelial cells is determined by the pH gradient. Journal of General Physiology 105(6): 861-896, 1995-06.

Díaz Nafría, J. M. (2010). What is information? A multidimensional concern. tripleC, 8(1), 77-108.

Díaz Nafría, J. M. \& Al Hadithi, B. (2009). Are 'the semantic aspects' actually 'irrelevant to the engineering problem'? tripleC, 7(2), 300-308.

Díaz Nafría, J. M. \& Al Hadithi, B. (2010). Fuzzy logic. In Díaz Nafría, J. M., Salto Alemany, F., \& Pérez-Montoro, M. (Eds.), Glossarium BITri: Glossary of concepts, metaphores, theories and problems regarding information. León, ES: Universidad de León. Retrieved from http://glossarium.bitrum.unileon.es/Home/logica-borrosa/fuzzy-logic.

Díaz Nafría, J.M. \& Salto Alemany, F. (2009). Introduction to the special issue "What is really information? An interdisciplinary approach. tripleC, $7(2)$, i-vi.

Dretske, F. I. (1981). Knowledge and the flow of information. Cambridge, MA: MIT Press.

European Bioinformatics Institute (EPI). (2010). Ligand-gated ion channel database. Retrieved from http://www.ebi.ac.uk/compneur-srv/LGICdb/LGICdb.php. 
Pérez-Montoro, M. (2007). The phenomenon of information. A conceptual approach to information flow. Lanham, MD: Scarecrow Press.

Richter, P. R., Ntefidou, M., Streb, C., Faddoul, J., Lebert, M., \& Häder, D.-P. (2002). High light exposure leads to a sign change of gravitaxis in the flagellate Euglena gracilis. Acta Protozool, 41, 343-351.

Shannon, C. E. \& Weaver, W. (1949). The mathematical theory of communication. Urbana, IL: The University of Illinois Press.

Zubiri, X. (1999). Sentient intelligence (T. B. Fowler, Trans.). Washington, DC: Xavier Zubiri Foundation of North America.

\begin{abstract}
About the Authors
José María Díaz Nafría

obtained M.Sc. in Telecommunication Engineering from the Universidad del País Vasco, Spain, and received his PhD in Telecommunication Engineering from the Universidad Politécnica de Madrid, Spain, with a dissertation on "Contributions to the electromagnetic inverse problem". He was also awarded with a M.A. in Philosophy by the Universidad Nacional de Educación a Distancia (UNED). He is currently visiting professor at the Munich University of Applied Sciences, investigator at the University of León and part of the board of directors of the Science of Information Institute, where he is also scientific advisor. He is member as well of several international scientific societies in the field of information theories.

He was research fellow at the Vienna University of Technology and at the Technical University of Madrid. He also served as professor at the University Alfonso X el Sabio in Madrid between 1997 and 2009. He has been visiting lecturer at the University of Furtwangen, Sankt Pölten University of Applied Sciences. Co-director of the "First International Meeting of Experts in Information Theories" (León, Spain, 2008) and the "Colloquium BITae" (León, Spain, 2009) currently coordinates an interdisciplinary research group meted around the BITrum project (Elucidation of the information concept) and co-edits with F. Salto and M. Pérez-Montoro the Glossarium BITri: glossary of concepts, metaphors, theories and problems concerning information (Universidad de León, 2010, http://glossarium.bitrum.unileon.es), where he authors several articles.
\end{abstract}

Mario Pérez-Montoro Gutierrez

Doctor in Philosophy and Education Sciences by the University of Barcelona, where he has been researcher at the Departamento de Lógica, Historia y Filosofía de la Ciencia. He studied in the Istituto di Discipline della Comunicazione in the Università di Bologna and was Visiting Scholar at the Center for the Study of Language and Information (CSLI) at Stanford University. He has been docent and researcher in several universities: Complutense de Madrid, Autònoma de Barcelona, Oberta de Catalunya and he is currently at the Department of Information Science at the University of Barcelona. One of his most known works is the book: The Phenomenon of Information (Scarecrow Press, 2007, published in Spanish by Trotta). He co-edits with J.M. Díaz and F. Salto the Glossarium BITri: glossary of concepts, metaphors, theories and problems concerning information (Universidad de León, 2010, http://glossarium.bitrum.unileon.es), where he authors several articles. 